\title{
In memoriam Prof. Franz Halberg (1919-2013)
}

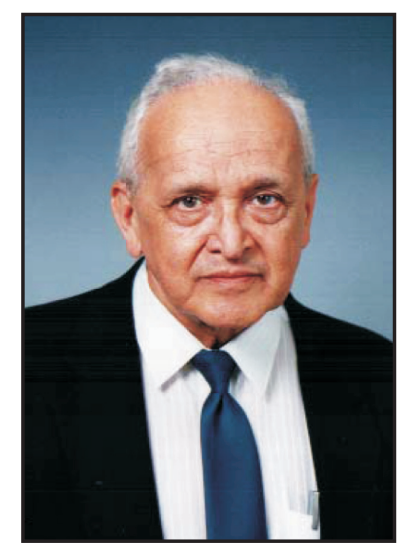

Time skipped a beat. On Sunday June 9, 2013, a legend, great scientist, and exceptional human being left us. His close associates also lost a dynamo, an inspiration, and a truly great friend. Franz Halberg's passing shy of his $94^{\text {th }}$ birthday leaves a void that cannot be filled. Franz will be remembered for founding the fields of chronobiology, chronomics and chronobioethics. His accomplishments are summarized in his over 3,400 scientific publications, in cooperation with colleagues from around the world. Many worldwide indeed call him their mentor and turned to him for advice, from study design and data analysis to the interpretation of results in the time dimension. Minnesota Medicine called him Father Time, and colleagues in Russia and Azerbaijan honored him as Lord of Time.

Born on July 5, 1919 in Romania, Franz studied the adrenal as a physician scientist in post-World War II Innsbruck, Austria. His work continued at Harvard Medical School, where he held a World Health Organization fellowship in clinical endocrinology in 1948. In 1949, he moved to the University of Minnesota, which saw his breakthrough experiments that led to the important discovery that circadian rhythms are partly endogenous and can be manipulated by environmental synchronizers, notably the lighting and feeding schedules. Franz coined the term circadian, after documenting that biologic rhythms tip the scale between health and disease and even between life and death. His results were widely published, including a 1969 citation classic. Franz went on to demonstrate that many other built-in cycles resonate in part with their counterparts in our broad environment. His recent work focused on building a growing edifice of shared periodicities with bridges across disciplines. He strived to understand how to enhance positive thoughts and emotions as a scaffold for tolerance and love by seeking optimal configurations of the time structured realm of the mind, what he called the chronosphere. He was a scholar in the true sense of the word, combining science, philosophy, poetry, and spirituality.

With applications in all fields of medicine and biology, Franz's legacy is far-reaching. He will be remembered for showing that timing cancer treatment according to marker rhythms improves outcomes both in terms of heightened efficacy and lesser undesired side effects, for showing that a calorie is different whether it is consumed at breakfast or dinner, and for his work in preventive cardiology by screening for abnormal patterns of blood pressure variability. Corresponding circadian timed treatment more than halved the risk of stroke and other adverse cardiovascular events. "Primum nil nocere" (above all, do no harm) prompted Franz to advocate the individualization of timed treatment, guided by marker rhythms.

His work earned him numerous awards, apart from holding professorships in Laboratory Medicine and Pathology, Physiology, Biology, Bioengineering and Oral Medicine at the University of Minnesota. He was a honorary member of the Romanian Academies of Science and Medical Sciences and received honorary doctorates from the University of Montpellier (France), Ferrara (Italy), Tyumen (Siberia), Brno (Czech Republic), L'Aquila (Italy), and People's Friendship University of Russia (Moscow, Russia). Franz was also an elected member of the prestigious Leibniz Society and of the International Academy of Science. His achievements in the new field of chronomics earned him the O.Yu. Schmidt Medal and diploma for outstanding merits in development of geophysics, the first such award given to a non-physicist.

Until his last breath, Franz strived to introduce timing for diagnosis, prognosis, treatment, and first and foremost prevention into clinical practice. At 93 years of age and still active 7 days a week in the Halberg Chronobiology Center at the University of Minnesota, which continues his work, he was the last recipient of a lifetime career award from the National Institutes of Health. Franz Halberg was a trail blazer who leaves a remarkable legacy. We shall all miss him deeply.

Germaine Cornelissen, Francine Halberg, Julia Halberg, Othild Schwartzkopff, Halberg Chronobiology Center, University of Minnesota, Minneapolis, MN, USA corne001@umn.edu 